\section{Diagnostic vascular ultrasonography with the help of color Doppler and contrast-enhanced ultrasonography}

\author{
Johannes Rübenthaler, Maximilian Reiser, Dirk-André Clevert \\ Department of Clinical Radiology, Ludwig-Maximilians-University of Munich-Grosshadern \\ Campus, Munich, Germany
}

The use of ultrasonography and especially of contrast-enhanced ultrasonography (CEUS) in the diagnosis of vascular pathologies before and after interventions has significantly increased over the past years due to the broader availability of modern ultrasound systems with CEUS capabilities and more trained user experience in this imaging modality. For the preinterventional and postinterventional work-up of carotid diseases, duplex ultrasound as well as CEUS have been established as the standard-of-care examination procedures for diagnosis, evaluation, and follow-up. In addition to its use for carotid arterial diseases, ultrasonography has also become the primary modality for the screening of vascular pathologies. This review describes the most common pathologies found in ultrasonography of the carotid arteries, the abdominal aorta, and the femoral arteries.

Keywords: Contrast media; Ultrasonography, contrast-enhanced; Carotid stenosis; Arteriovenous fistula; Dissection; Plaque, atherosclerotic

\section{Introduction}

The initial diagnostic workup of patients suspected of suffering from carotid artery disease is duplex ultrasonography of the carotid vessels (Fig. 1) [1-7]. Duplex ultrasonography is also the preferred imaging modality for the follow-up of patients after stent implantation or endarterectomy $[8,9]$. Among patients showing amaurosis fugax or hemispheric transient ischemic attacks, $88 \%$ reveal atherosclerotic plaques at the carotid bifurcation [10] and about $25 \%-50 \%$ of all strokes are a result of ruptured atherosclerotic plaques; in addition, about $80 \%$ of all strokes are of ischemic origin [1113]. Internal carotid artery (ICA) stenosis quantification is essential for the clinical management of patients, since several trials have concluded that symptomatic patients with high-grade stenosis (70\%-90\%) of the ICA, as well as asymptomatic patients with high-grade stenosis, benefit from carotid endarterectomy (CEA) [14-18].

In abdominal ultrasonography, abdominal aortic aneurysms (AAAs) are found in $2 \%$ to $8 \%$ of men over the age of 65 years, with incidence in women that is lower by a factor of 4 [19]. All AAAs are defined as an enlargement of the abdominal aorta greater than $3.0 \mathrm{~cm}$ or greater than $50 \%$ of normal size [19]. About $85 \%$ of all AAAs are detected below the origin of the kidney vessels [19].

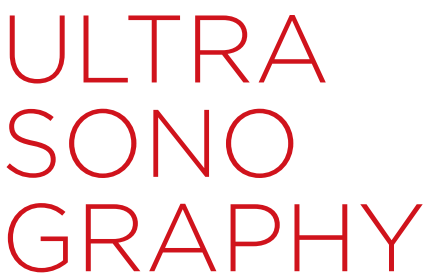

\section{REVIEW ARTICLE}

http://dx.doi.org/10.14366/usg.16027 pISSN: 2288-5919 - elSSN: 2288-5943

Ultrasonography 2016;35:289-301

Received: May 26, 2016

Revised: August 12, 2016

Accepted: August 12, 2016

Correspondence to:

Dirk-André Clevert, MD, Department of Clinical Radiology, Munich University Hospital, Marchioninistr. 15, 81377

Munich, Germany

Tel. +49-89-44007-3620

Fax. +49-89-44007-8832

E-mail: Dirk.Clevert@med.unimuenchen.de

This is an Open Access article distributed under the terms of the Creative Commons Attribution NonCommercial License (http://creativecommons.org/ licenses/by-nc/3.0/) which permits unrestricted noncommercial use, distribution, and reproduction in any medium, provided the original work is properly cited.

Copyright (C) 2016 Korean Society of Ultrasound in Medicine (KSUM)

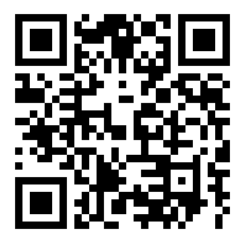

How to cite this article:

Rübenthaler J, Reiser M, Clevert DA. Diagnostic vascular ultrasonography with the help of color Doppler and contrast-enhanced ultrasonography. Ultrasonography. 2016 Oct:35(4):289-301. 


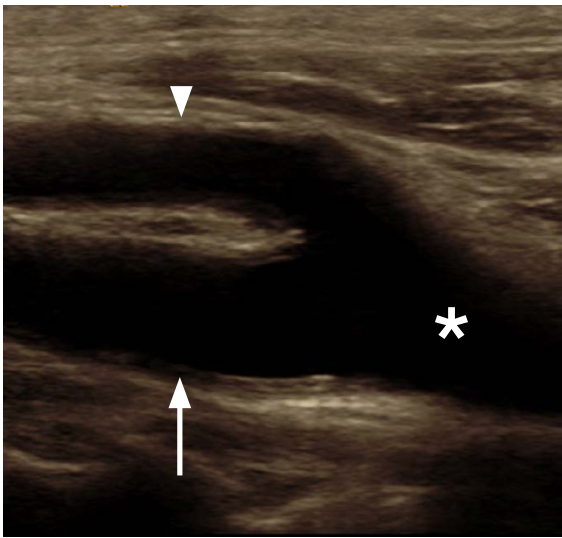

A

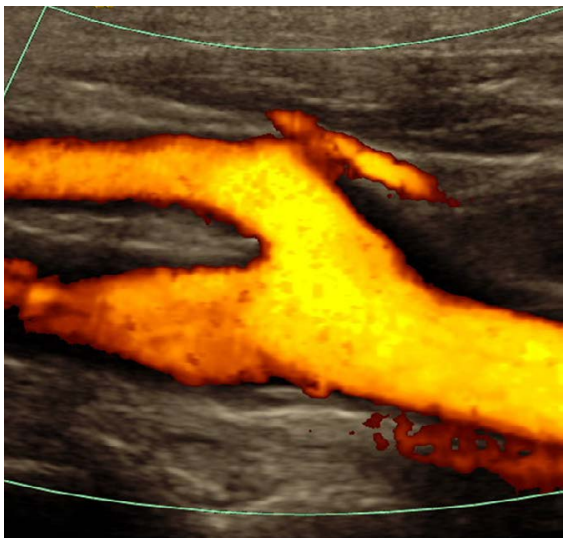

B

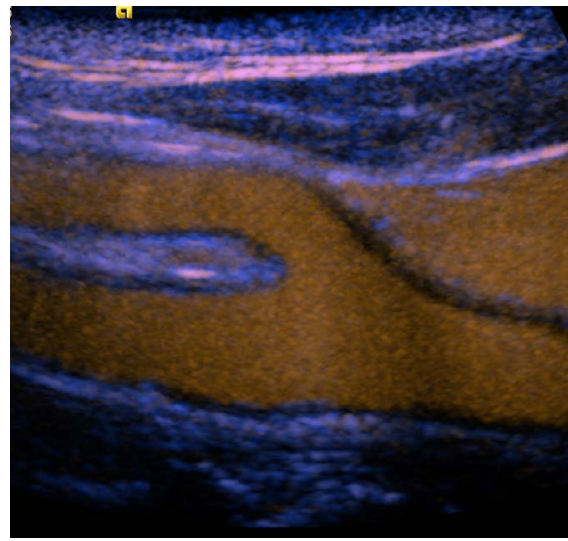

C

Fig. 1. Ultrasonography of a carotid bulb.

A, B. B-Scan (A) and color Doppler (B) sonograms of the carotid bulb demonstrate the distal common carotid artery (asterisk), the proximal internal carotid artery (ICA) (arrow) and external carotid artery (ECA) (arrowhead). C. Contrast-enhanced ultrasonography of the carotid bulb demonstrates the perfused lumen of distal common carotid artery, the proximal ICA and ECA.

Surgical intervention is recommended at any diameter greater than $5.5 \mathrm{~cm}$ in men or $5.0 \mathrm{~cm}$ in women [19]. The main risk is a rupture, with a risk of less than $1 \%$ for aneurysms with a size of less than $5.5 \mathrm{~cm}, 10 \%$ for aneurysms with a diameter between 5.5 $\mathrm{cm}$ and $7.0 \mathrm{~cm}$, and $33 \%$ for aneurysms larger than $7.0 \mathrm{~cm}$ [19]. A ruptured AAA shows a mortality rate of $85 \%$ to $90 \%$ [19]. Clinical management includes conservative treatment with follow-up ultrasonography for asymptomatic AAAs with a diameter less than $5.5 \mathrm{~cm}$, as there is a higher risk of peri-interventional complications than of rupture and surgical repair for AAAs above that size, with contrast-enhanced ultrasonography (CEUS) follow-up examinations after endovascular aneurysm repair (EVAR) [20-28].

Duplex ultrasonography is also the imaging modality of choice for the detection of complications after puncture of the femoral artery, as they occur in $0.1 \%-9 \%$ of cases with aneurysms, with arteriovenous fistulas, dissections, and hematomas being the most common complications [29-34].

\section{Contrast-Enhanced Ultrasonography Technique}

With the implementation of specific contrast modes in modern ultrasound systems and the broader availability of these systems in the clinical routine, CEUS can be used for the assessment of vascular complications. Modern contrast modes use a low mechanical index mode that processes the non-linear signals emitted by the microbubbles of the contrast agent and separates out the signals of the tissue and the contrast agent $[35,36]$. The contrast agent is intravenously administered through a needle of at least 18G. The microbubbles oscillate in response to the emitted ultrasound and reflect an echo with an amplified echo intensity of up to $30 \mathrm{~dB}$ $[35,37]$. Major side effects must be taken into consideration, which are comparable to those of contrast agents used for other imaging modalities. The most important possible side effect of an ultrasound contrast agent is an anaphylactic reaction, which is described to occur in one out of 10,000 cases $[38,39]$.

SonoVue (Bracco, Milan, Italy), most commonly used among modern ultrasonography contrast agents, consists of phospholipid shells, which stabilize microbubbles, and their core, containing sulphur hexafluoride (SF6) gas. Once administered, the ultrasound contrast agent is quickly eliminated. The phospholipids are metabolized endogenously and the SF6 gas is exhaled via the lungs within a time period of up to 8 minutes. At 2-10 $\mu \mathrm{m}$, a single microbubble is about the size of an average erythrocyte. For diagnostic views of the vessels, 1.6 to $2.4 \mathrm{~mL}$ of contrast agent should be intravenously administered as a bolus injection, followed by a flush of $5-10 \mathrm{~mL}$ of saline solution $(0.9 \% \mathrm{NaCl})$ in order to achieve good contrast [40].

\section{Carotid Arterial Diseases}

\section{Stenosis}

About $10 \%-15 \%$ of all strokes and transitory attacks of ischemic origin are the consequence of an atherosclerotic stenosis of the ICA, especially of the proximal part [41]. Most important in the initial workup of ICA stenosis is the differentiation between a total occlusion of the ICA or a preocclusive stenosis that is characterized as a stenosis of at least 90\% [42-47]. Preocclusive symptomatic stenosis can be treated with surgical intervention or 
with other interventional measures in order to prevent a threatening hemiparesis [3,6]. With sensitivities between $86 \%$ and $98 \%$ and specificities between $87 \%$ and $100 \%$, vascular ultrasonography of the ICA has a high diagnostic accuracy in the characterization of ICA stenosis and in the differentiation of ICA occlusions, dependent on examiner experience and parameter settings [48-50]. With CEUS, it is even possible to advance the visualization of carotid artery diseases by detecting the blood flow through the stenosis even in elongated vessels, without the disadvantage of an angle dependency or aliasing or blooming flow artifacts (Fig. 2) [51-55].

\section{Postinterventional Follow-up}

The traditional method of choice for the treatment of symptomatic and asymptomatic patients with ICA stenosis is the CEA $[47,56]$.
Carotid artery stenting (CAS) is an alternative to the traditional CEA, especially in patients with a high risk of complications from undergoing surgery, for example, patients with significant cardiopulmonary disease [57-59]. The use of CEA carries a risk of restenosis of about $25 \%$, whereas the risk of restenosis after CAS is below $5 \%$ in most cases in the initial 5 years after stenting $[9,60-$ 63]. Duplex ultrasonography and CEUS are the imaging modalities of choice for postinterventional surveillance for restenosis after CAS and for the characterization of in-stent restenosis after stenting, with CEUS providing a reduction of flow artifacts and a better visualization of the morphology of the restenosis compared to color and power Doppler (Fig. 3) [64-66].

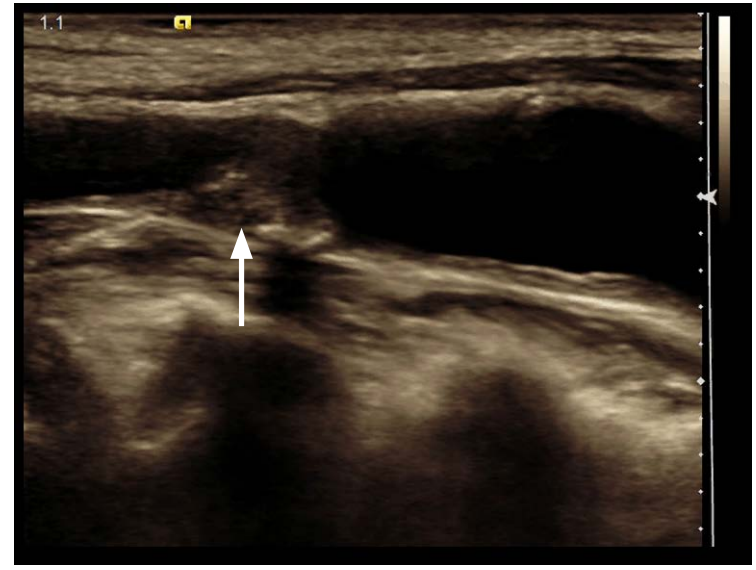

A

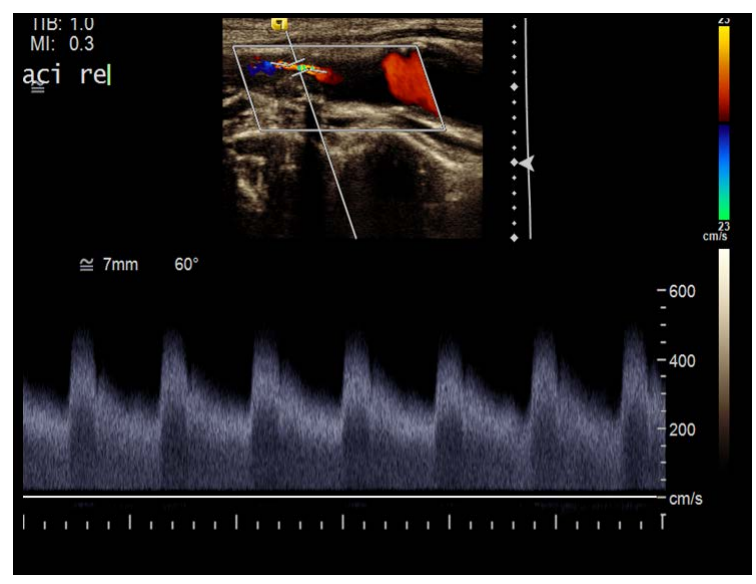

C

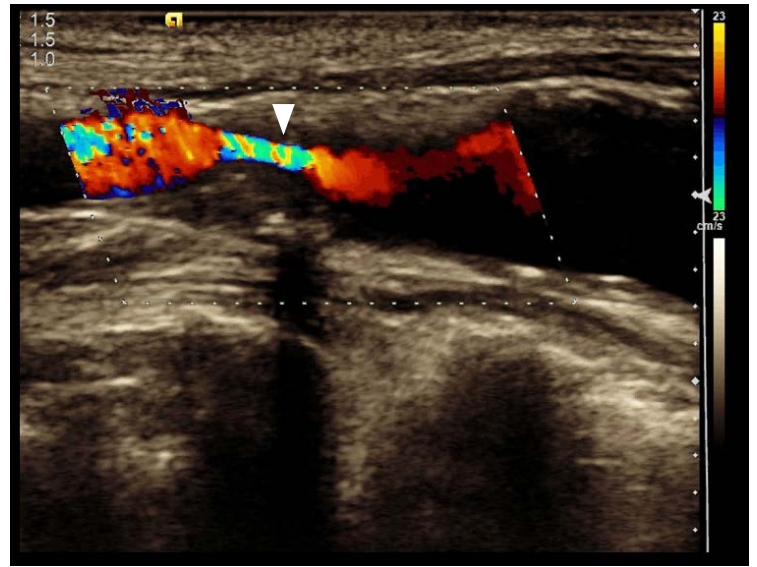

B

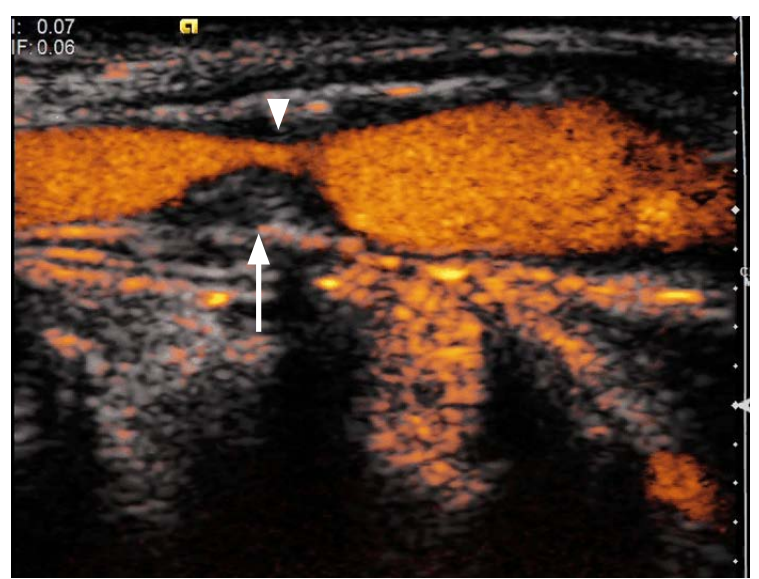

D

Fig. 2. Ultrasonography of a 67-year-old woman with recent ischemic neurological symptoms.

A. B-Scan shows a high-degree internal carotid artery (ICA) stenosis with soft plaques (arrow). B, C. Duplex ultrasonography shows a highdegree stenosis of the ICA (arrowhead) with a maximal systolic flow velocity of about $500 \mathrm{~cm} / \mathrm{sec}$. D. Contrast-enhanced ultrasonography (CEUS) detects the intrastenotic flow (arrowhead) without overwriting the wall of the vessel and reveals the complete residual lumen and the length of the stenosis. Additionally, CEUS confirms the absence of intraplaque neovascularization (arrow). 


\section{Dissection}

Cervical dissections are rather uncommon and can be divided into spontaneous or traumatic dissections. The annual incidence of dissections is about $1-3$ out of 100,000 cases, and they account for $15 \%-20 \%$ of all cerebral infarctions in adolescents [67]. Clinical symptoms of dissections vary acutely from individual to individual [68]. Vascular ultrasonography is the imaging modality of choice for the detection and characterization of acute dissection by imaging the mural hematoma as well as the false and true lumen, along with the normal visualization of a decreased blood volume flow in the false lumen that results in an increased risk for thrombosis, embolization, or even partial or total occlusion of the artery [69-71]. Modern ultrasound probes can even identify a small dissection with very thin membranes of less than $1 \mathrm{~mm}[4,72,73]$. The use of CEUS can aid diagnosis and improve diagnostic accuracy in difficult cases $[51,53]$.

\section{Complications after Intervention}

With an incidence of about $2 \%-10 \%$, the puncture of the carotid artery is the most common complication after central venous catheterization of the internal jugular vein $[74,75]$. This intervention is mostly performed at the intensive care unit or for interventional radiological procedures. The most important complication is an arteriovenous fistula that can occasionally be seen clinically as a swelling of the neck, sometimes pulsatile [76]. Duplex ultrasonography and CEUS are the imaging modalities of choice for the detection of arteriovenous fistulae, with CEUS being the superior imaging technique because of its independence from aliasing or overwriting artifacts (Fig. 4) $[5,77,78]$.

\section{Plaque Characterization}

Ulcerating plaques are thought to be a factor in the aetiology of strokes from carotid arterial diseases $[79,80]$. The use of CEUS is an imaging modality option for detecting plaque ulceration that might

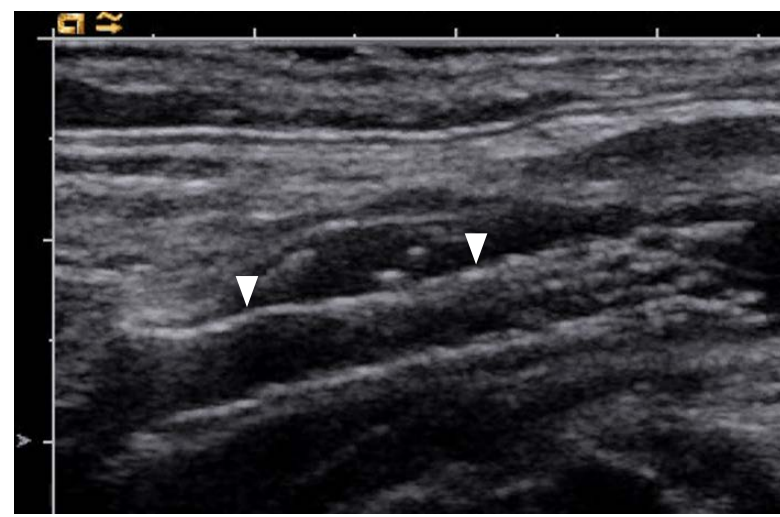

A

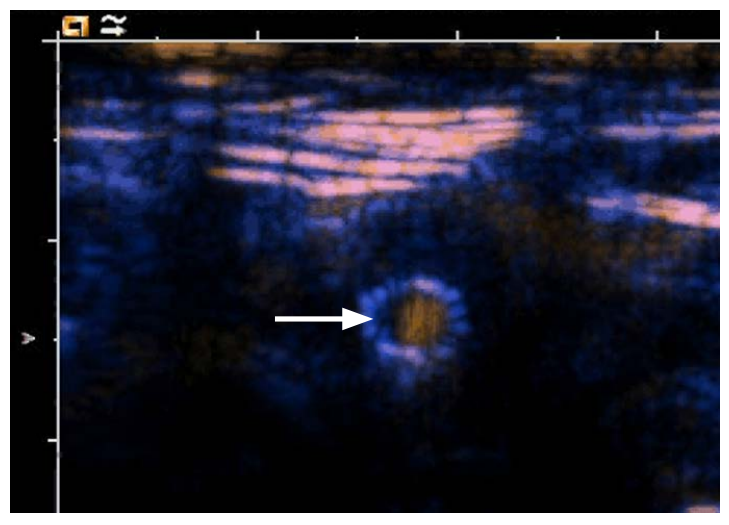

C

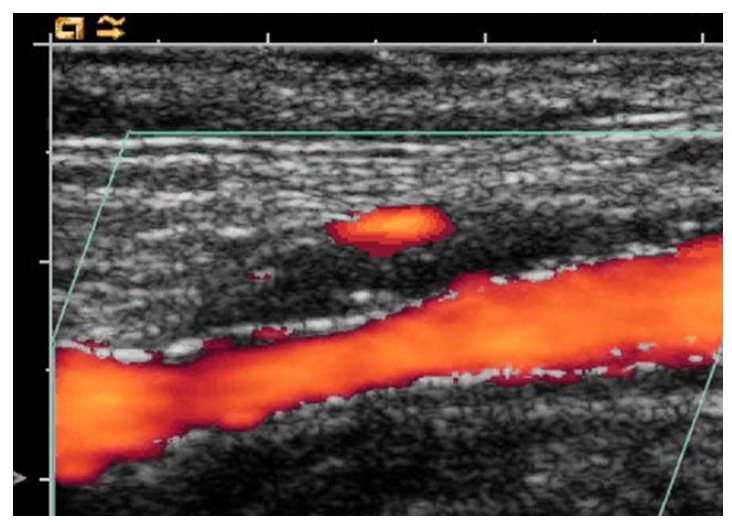

B

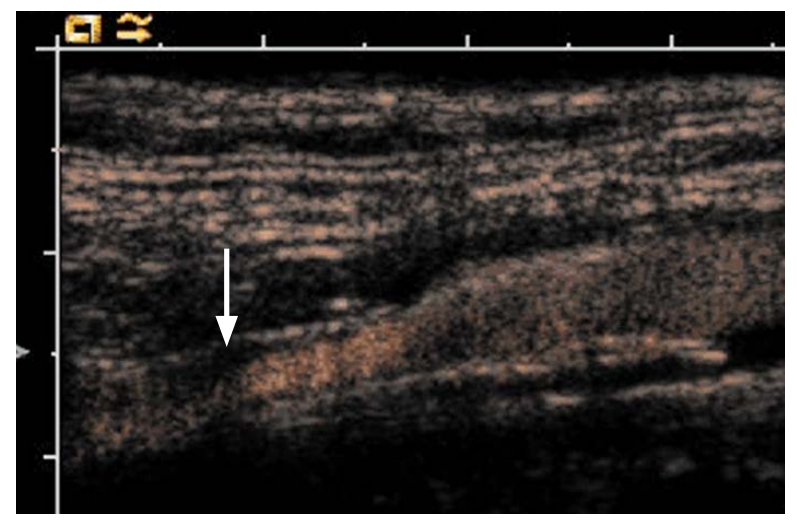

D

Fig. 3. Longitudinal ultrasonography after internal carotid artery (ICA) stent insertion.

A. B-Scan shows an ICA stent (arrowheads). B. Power Doppler ultrasonography could not depict any in-stent stenosis. C. Cross-sectional contrast-enhanced ultrasonography (CEUS) image of the ICA stent shows the semi-circular soft plaque (arrow) and the remaining perfused lumen of the ICA stent. According to the criteria of an area stenosis, the degree of the in-stent stenosis will be about $40 \%-50 \%$. D. CEUS shows some soft plaques (arrow) at the anterior ICA stent wall. 
be caused by inflammatory processes and neovascularization inside the plaque; it assesses the contrast uptake in plaques via time-signal intensity curves (Fig. 5) [52,81-84].

\section{Abdominal Aortic Aneurysm}

\section{Abdominal Aortic Aneurysm}

AAAs are defined as an enlargement of the abdominal aorta greater than $3.0 \mathrm{~cm}$ or greater than $50 \%$ of normal size [19]. A ruptured AAA shows a mortality rate of $85 \%$ to $90 \%$ and is the 10 th most common cause of death in men over the age of $55[19,20]$. Immediate treatment of a ruptured AAA is essential, as an untreated ruptured AAA is most likely to result in death [20]. About $85 \%$ of all AAAs are detected below the origin of the kidney vessels [19].
Surgical intervention is recommended at any diameter greater than $5.5 \mathrm{~cm}$ in men or $5.0 \mathrm{~cm}$ in women [19]. The main risk is a rupture, with a risk of less than $1 \%$ for aneurysms with a diameter of less than $5.5 \mathrm{~cm}, 10 \%$ for aneurysms with a diameter between 5.5 and $7.0 \mathrm{~cm}$ and $33 \%$ for aneurysms with a diameter greater than $7.0 \mathrm{~cm}$ [19]. With a sensitivity of $95 \%-98 \%$, duplex ultrasonography is the initial imaging method of choice for the diagnosis of AAAs [85]. The use of CEUS can help visualize the direct signs of a rupture (Fig. 6) [86].

\section{Postinterventional Follow-up}

After EVAR of an AAA, the stent needs lifelong imaging surveillance in order to detect complications like endoleaks, fractures, or a progressive enlargement of the AAA [27]. After EVAR, CEUS is the

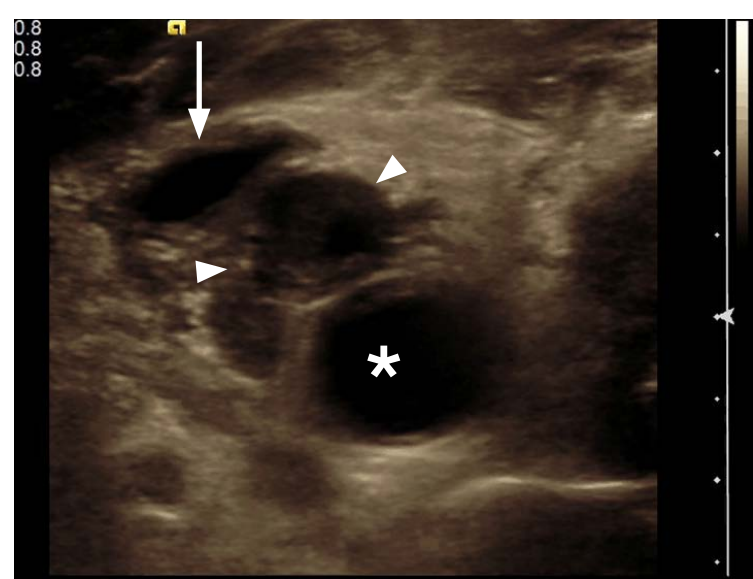

A

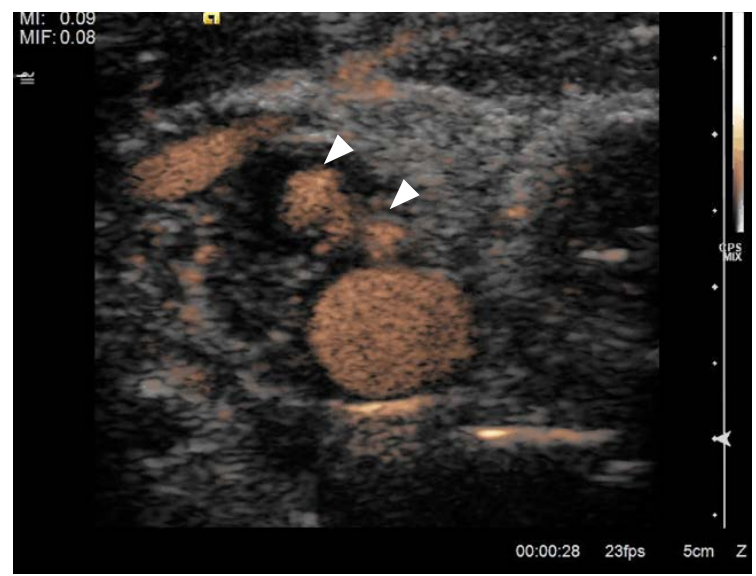

C

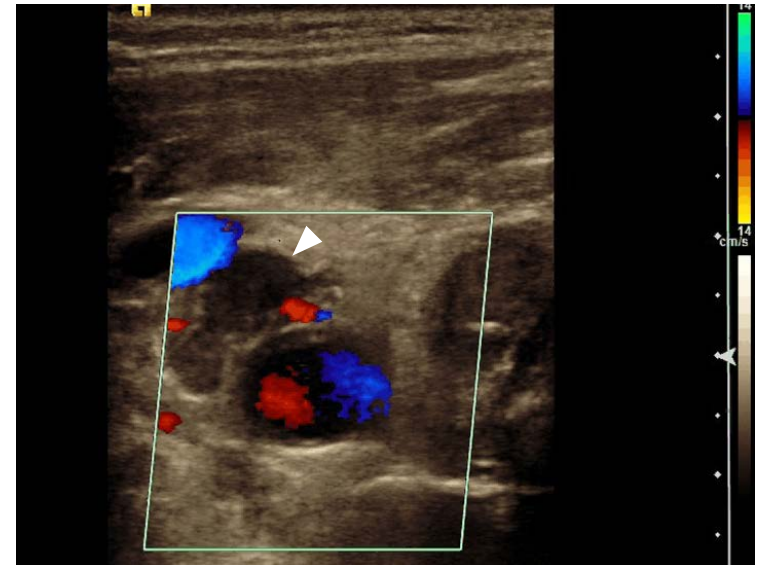

B

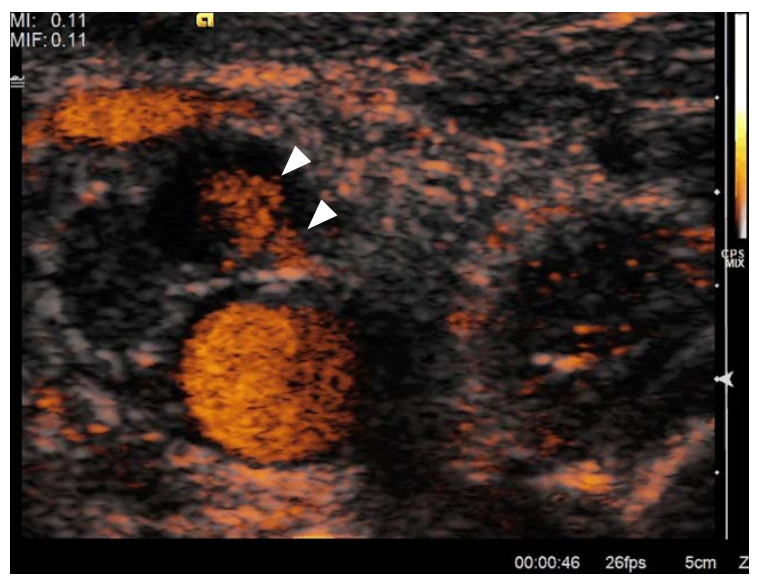

D

Fig. 4. Ultrasonography after central line placement.

A. Cross-sectional B-scan identifies a hypo-echoic structure suggesting hematoma (arrowheads) without communication between the common carotid artery (asterisk) and the internal jugular vein (arrow). B. The hematoma does not show any perfusion (arrowhead) on color Doppler sonogram. C, D. Contrast-enhanced sonograms of the common carotid artery demonstrate the uptake of contrast inside the hematoma (arrowheads) as the presence of a pseudo-aneurysm after central line placement without aliasing or any overwriting artifacts. 


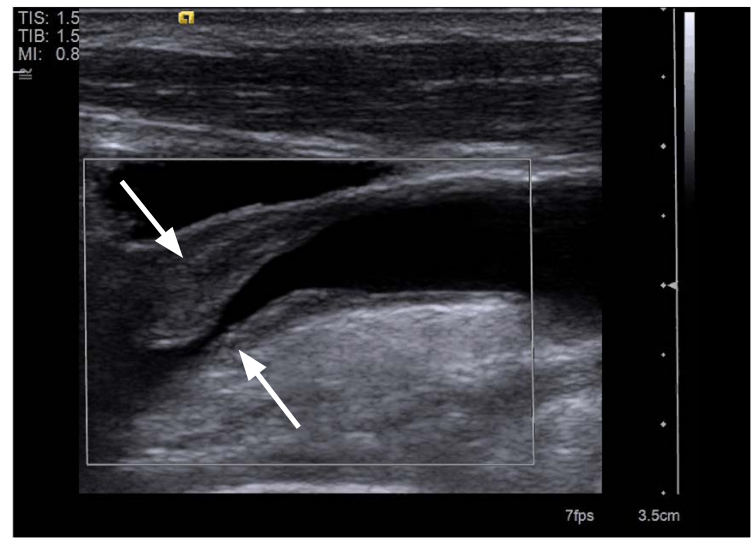

A

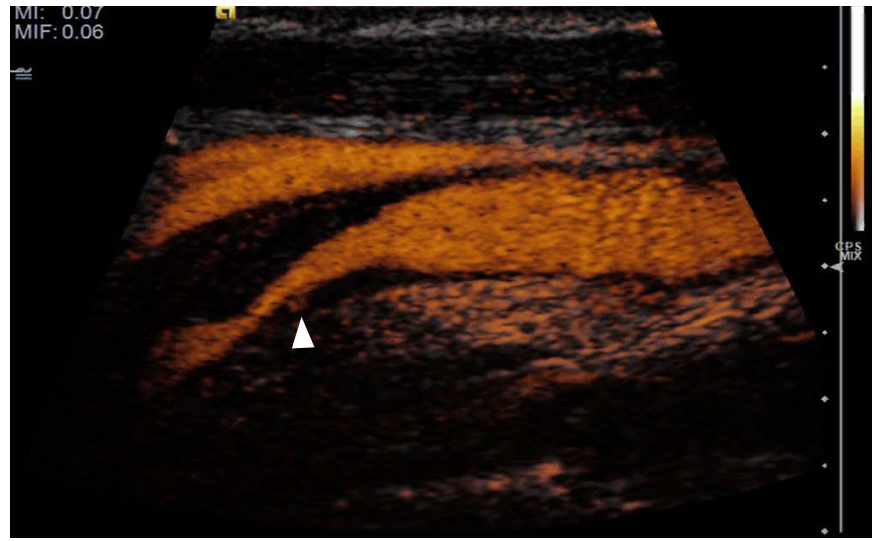

B

Fig. 5. Ultrasonography of an atheromatous plaque in the carotid artery.

A. B-Scan of show a significant stenosis by atheromatous plaques (arrows). B. Contrast-enhanced ultrasonography shows a neovascularization inside the plaque (arrowhead) as a sign of plaque vulnerability.

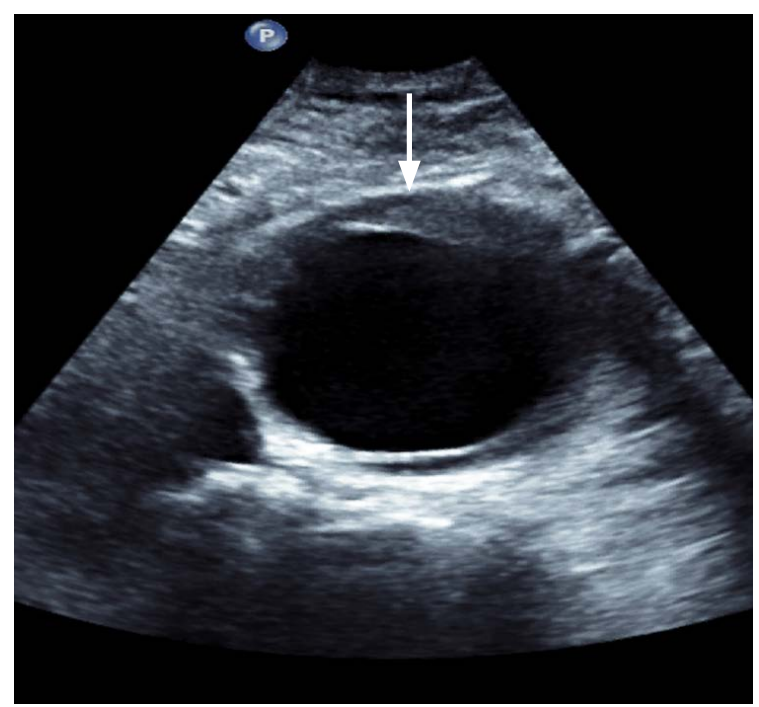

A

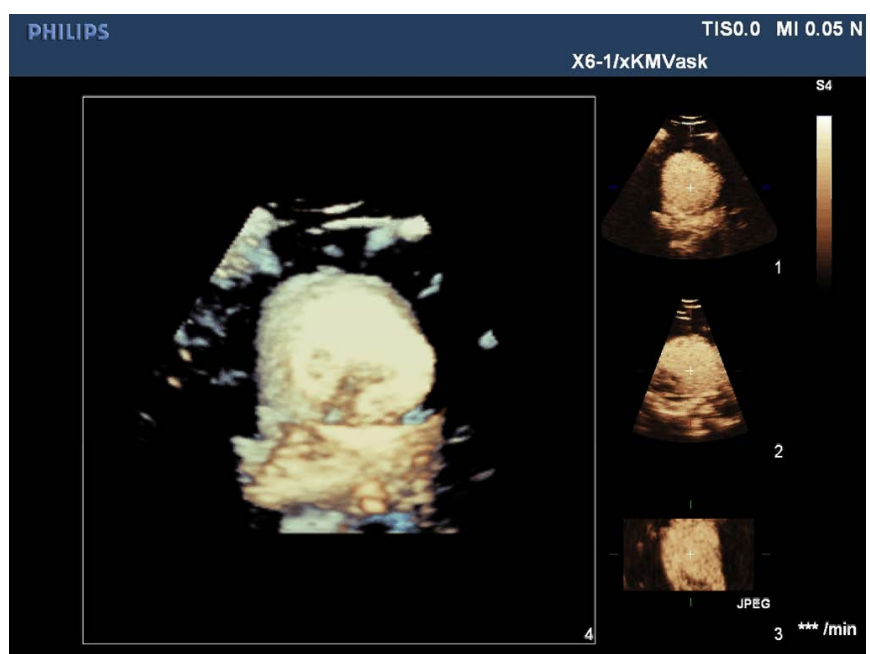

C

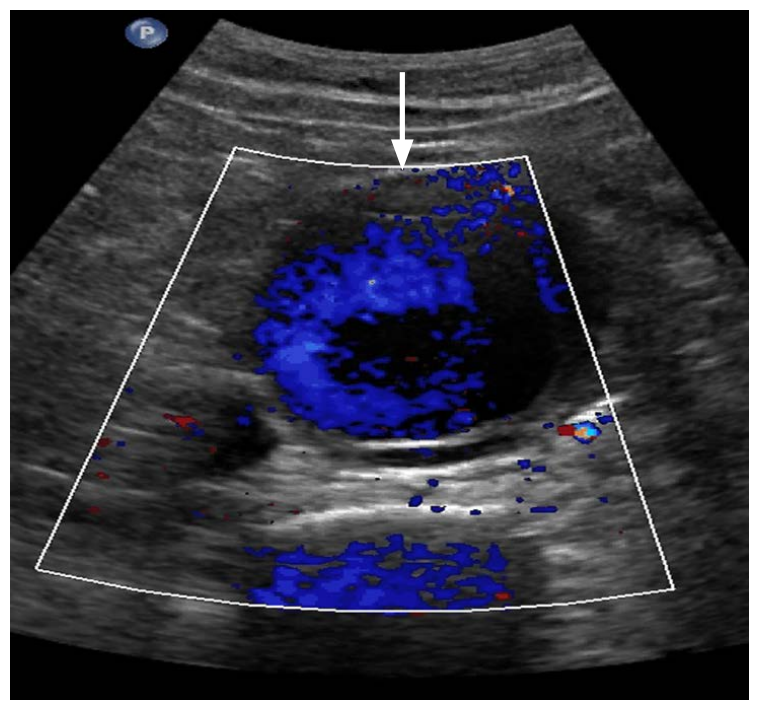

B

Fig. 6. Ultrasonography of an infrarenal aortic aneurysm.

A, B. B-Scan (A) and color Doppler (B) sonograms demonstrate infra-aortic aneurysm (arrows). C. Real time-resolved 4D contrastenhanced ultrasonography shows the same infrarenal aortic aneurysm in the $x$-plane (right top), $y$-plane (right middle), and z-plane (right bottom) with a volume image (left). 
imaging modality of choice, as it allows a fast and noninvasive diagnosis during follow-up. The sensitivity and specificity for the detection of endoleaks is $98 \%-100 \%$ and $82 \%-93 \%$, respectively (Fig. 7) [21].

\section{Vascular Complications after Transfemoral Puncture}

\section{Pseudoaneurysms}

False aneurysms or pseudoaneurysms after transfemoral puncture occur in $0.05 \%-9 \%$ of all cases $[29,87-89]$. They are characterized as a rupture in the layer of the wall of an artery that does not occlude after puncture. The leaking blood causes a pulsatile hematoma that forms a blood-filled cavity that is fed through a connection between the cavity and the punctured artery. With increasing size there is an increased risk for rupture, making a rapid diagnosis essential [90]. Duplex ultrasonography and CEUS are the imaging modalities of choice for the detection of pseudoaneurysms, with CEUS being the preferred imaging technique because it is independent of aliasing or overwriting artifacts (Fig. 8) [91].

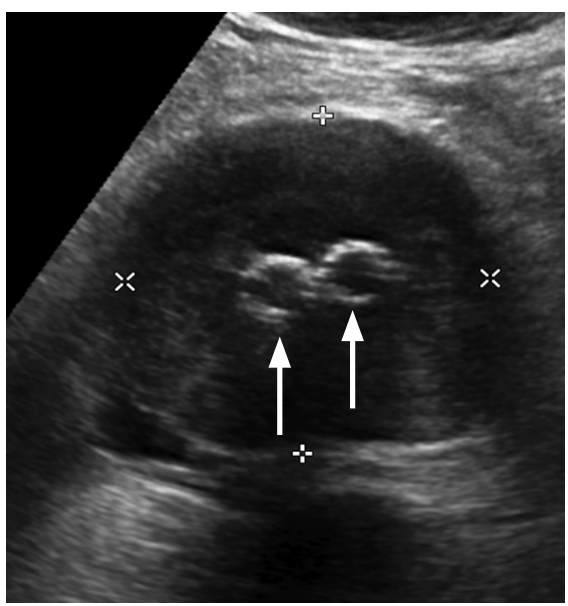

A

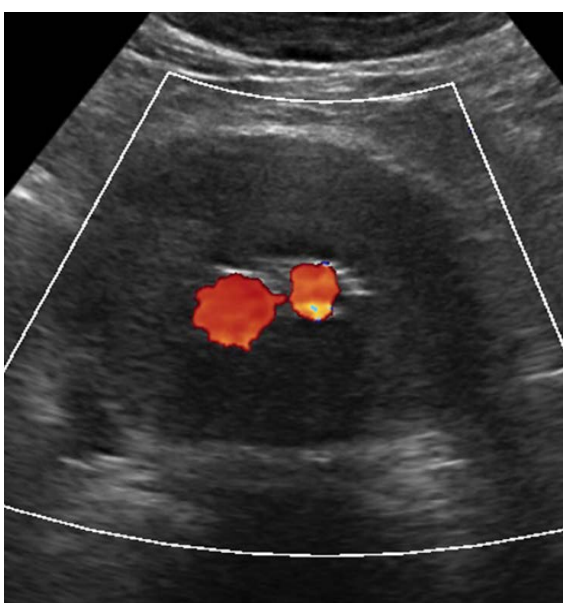

B

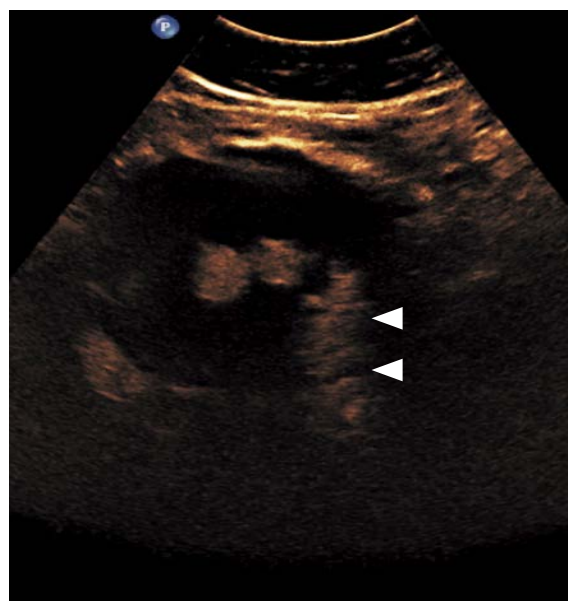

C

Fig. 7. Ultrasonography of the abdominal aortic aneurysm after endovascular aneurysm repair.

A, B. Cross-sectional B-scan (A) and color Doppler (B) sonograms show aortic aneurysm (crosshairs) with right and left stent graft legs (arrows). No endoleak was detected. C. Contrast-enhanced ultrasonography shows a type II endoleak (arrowheads) over the left lumbar artery.

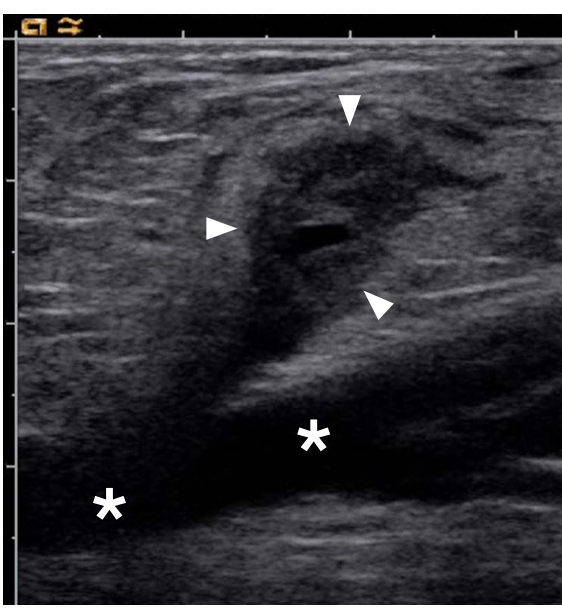

A

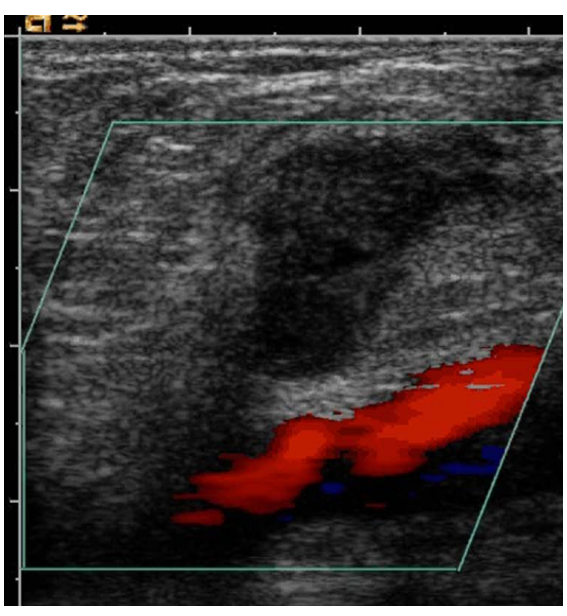

B

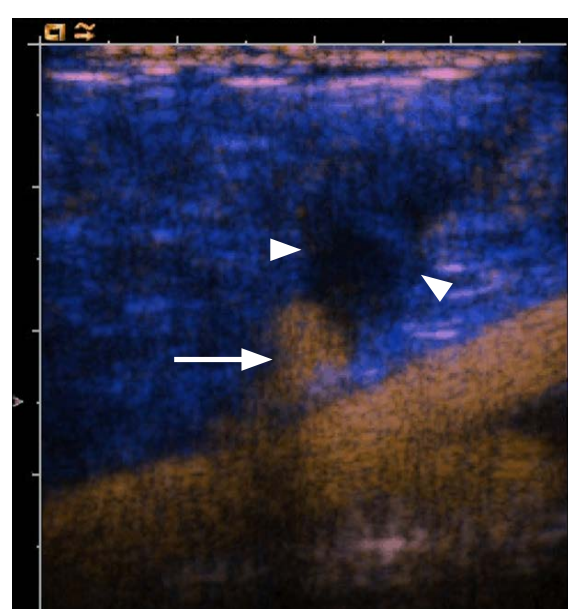

C

Fig. 8. Ultrasonography of the femoral artery after catheter intervention.

A, B. Cross-sectional B-scan (A) and color Doppler (B) sonograms of femoral artery (asterisks) delineate a pseudoaneurysm (arrowheads) without any discernable flow signal. C. Contrast-enhanced ultrasonography shows a partial perfusion (arrow) of pseudoaneurysm, while the distal part does not show any perfusion (arrowheads). 


\section{Arteriovenous Fistula}

Arteriovenous fistulae occur in $0.1 \%-3.6 \%$ of all cases after transfemoral puncture $[29,34,88]$. They are described as iatrogenically abnormally connected arteries and veins. If the fistula is large enough, they can be hemodynamically relevant, causing a decrease in peripheral resistance [92]. Arteriovenous fistulae show a tendency to increase in size, making surgical treatment the intervention of choice in many cases. In some cases, the arteriovenous fistula occludes spontaneously or can be compressed via ultrasonography [76]. Duplex ultrasonography and CEUS are the imaging modalities of choice for the detection of arteriovenous fistulae, with CEUS being the superior imaging technique because of its independence from aliasing or overwriting artifacts (Fig. 9) $[5,77,78]$.

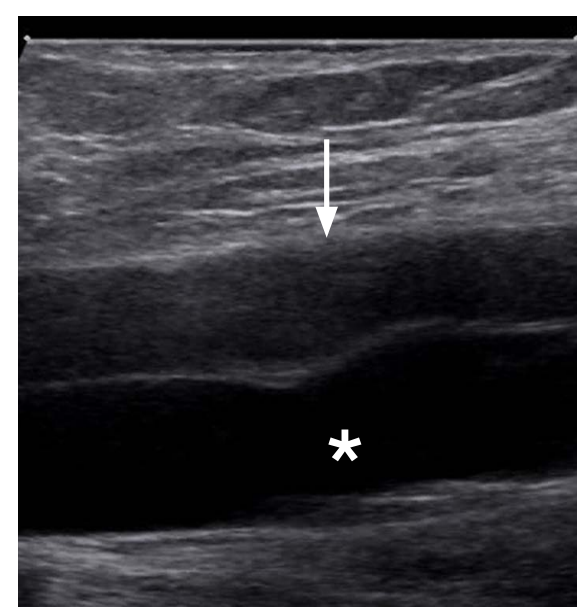

A

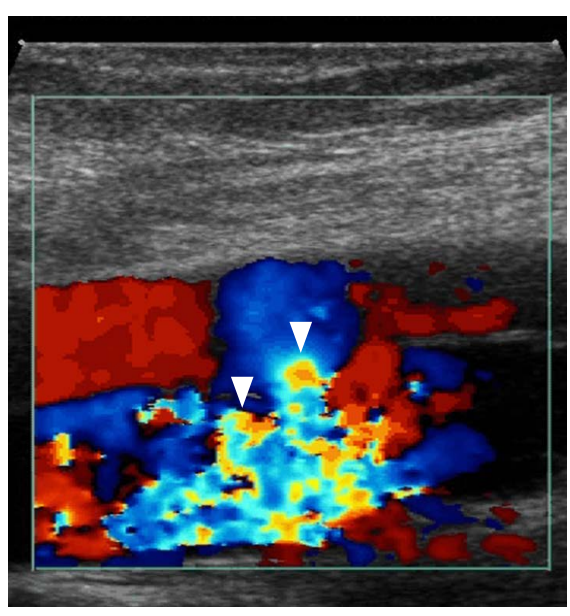

B

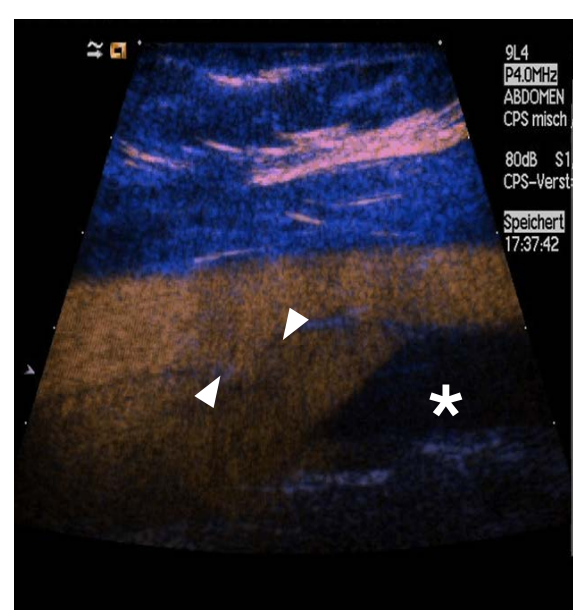

C

Fig. 9. Ultrasonography of the femoral artery after catheter intervention.

A, B. On cross-sectional B-scan (A) and color Doppler (B) sonograms, arteriovenous fistula with turbulent blood flow in the arteriovenous fistula track (arrowheads) is depicted between the common femoral artery (arrow) and vein (asterisk). The complete extent of the fistulous track is due to aliasing demarcated. C. Contrast-enhanced ultrasonography of the common femoral artery and vein identified the complete extent of the arteriovenous fistulous track (arrowheads) and confirmed the presence of an arteriovenous communication without aliasing or any overwriting artifacts. The distal part of the common femoral vein (asterisk) does not show any contrast uptake due to the arterial scanning.

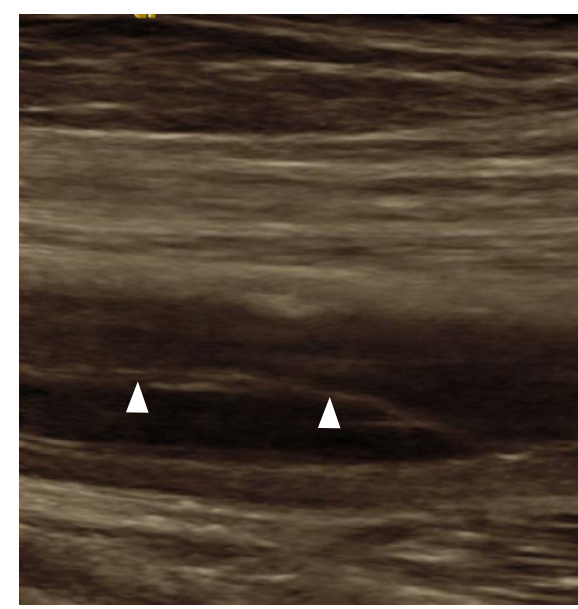

A

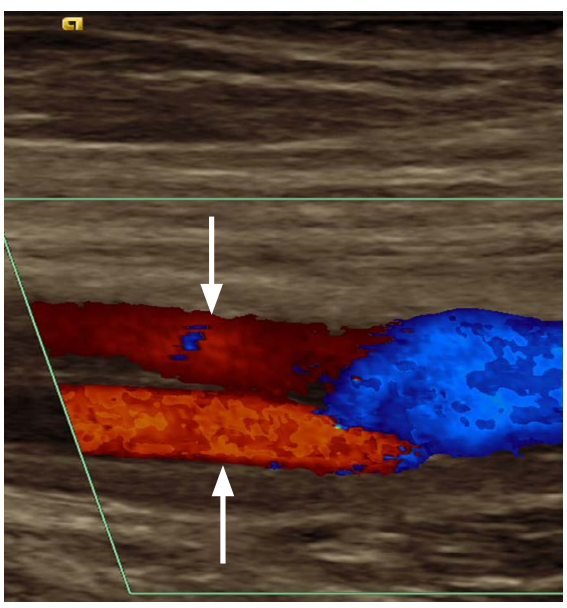

B

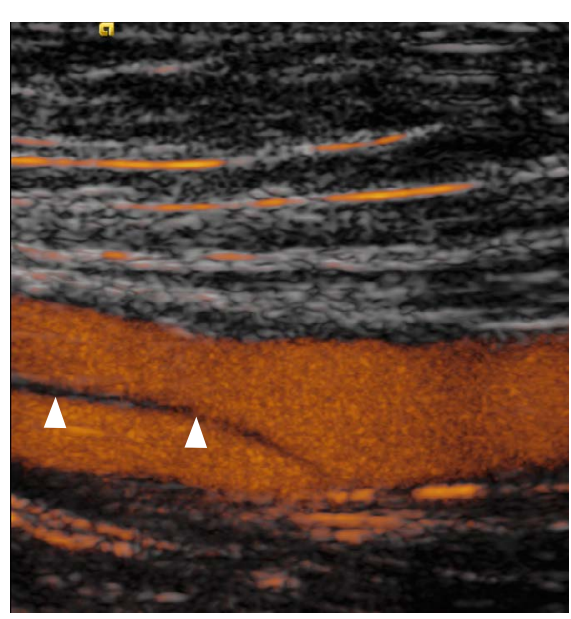

C

Fig. 10. Ultrasonography of common femoral artery dissection.

A, B. B-Scan (A) and color Doppler (B) sonograms show the common femoral artery with intimal dissection (arrowheads). Both lumens are perfused in the color Doppler setting (arrows). C. Due to its superior spatial resolution, the dissection membrane (arrowheads) and both perfused lumens are clearly depicted on contrast-enhanced ultrasonography. 


\section{Dissection}

Dissections occur in $0.3 \%-3.6 \%$ of all cases after transfemoral puncture $[66,93]$. Similarly as was described before for the dissection of the carotid arteries, vascular ultrasonography is the imaging modality of choice for the detection and characterization of dissection, by showing the mural hematoma as well as the false and true lumen, and by additionally visualizing any decreased blood volume flow in the false lumen that results in an increased risk for thrombosis, embolization, or even partial or total occlusion of the artery [69-71]. As discussed before, modern ultrasound probes can identify small dissection with very thin membranes of less than $1 \mathrm{~mm}[4,72,73]$. CEUS can help aid diagnosis and improves the diagnostic accuracy in difficult cases (Figs. 10,11) [51,53].

\section{Hematoma}

Hematomas occur in $0.4 \%-11 \%$ of all cases after transfemoral puncture $[29,66,94]$ and are a rather common complication in this circumstance. Normally, hematomas are locally limited and are resorbed within a short period of time. They can be easily depicted using duplex ultrasonography.

\section{Conclusion}

For the detection, characterization, and follow-up of vascular pathologies, duplex ultrasonography is the first choice. However, duplex ultrasonography has technical limitations in diagnostic use, for example, due to aliasing artifacts that can complicate diagnosis. The use of CEUS can increase the diagnostic performance in difficult vascular disorders compared to duplex ultrasonography. Thus, CEUS has become a promising, safe, noninvasive imaging tool in different aortic pathologies, particularly for the detection of endoleaks following endovascular treatment of AAAs. Examinations

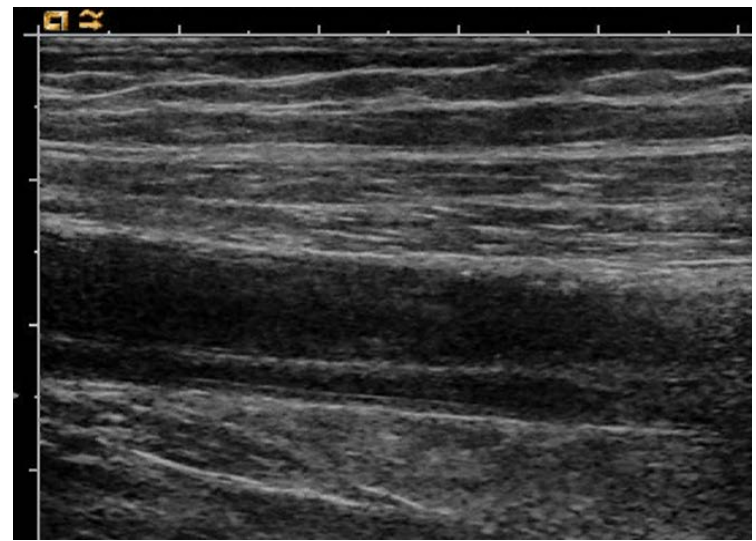

A

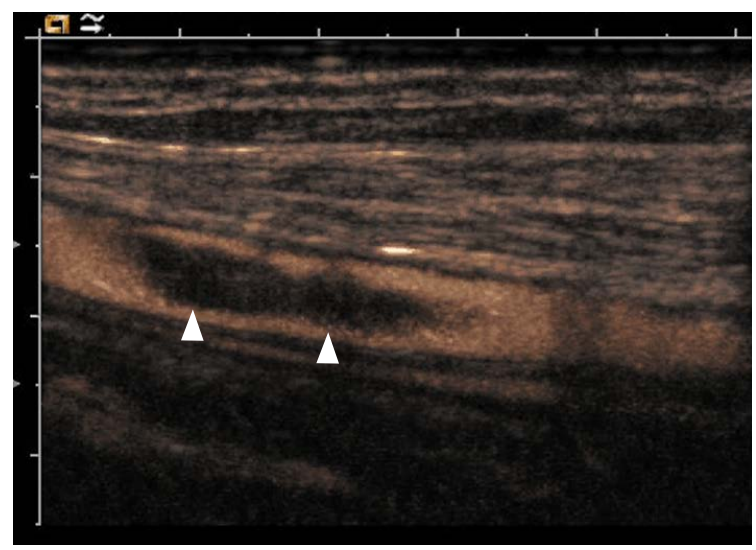

C

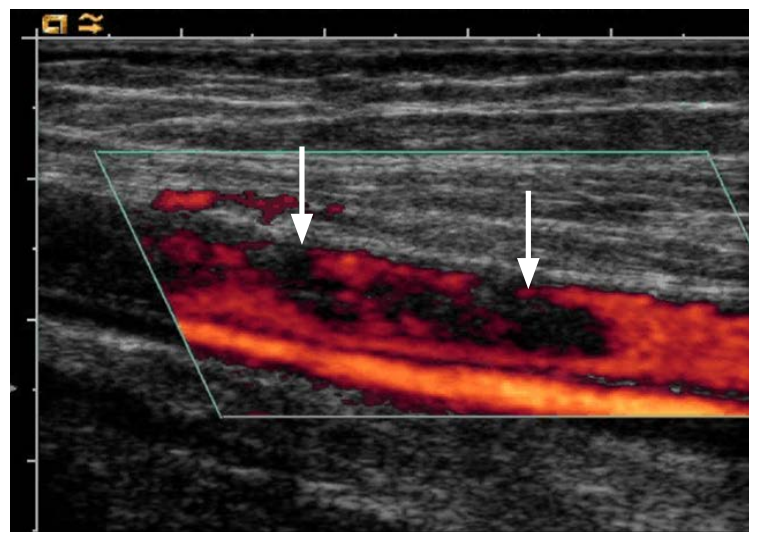

B

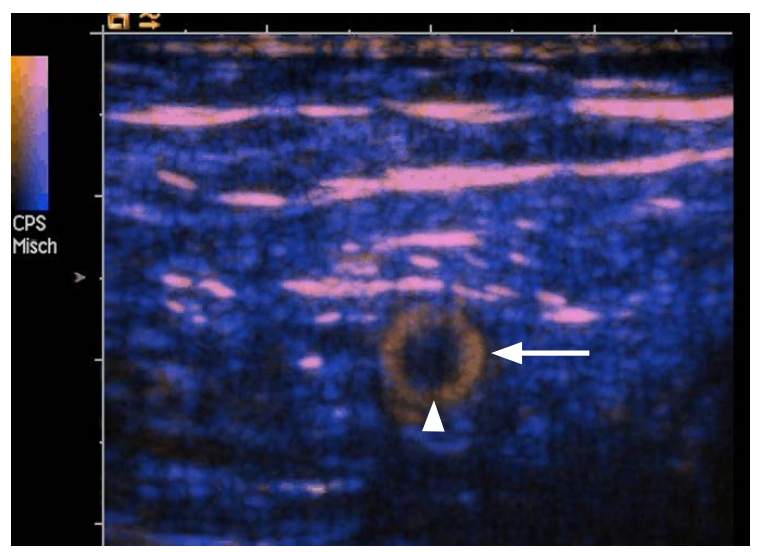

D

Fig. 11. Ultrasonography of the common femoral artery with suspicious dissection.

A, B. B-Scan (A) and color Doppler (B) sonograms show incomplete perfusion of the vessel lumen (arrows). C, D. Longitudinal (C) and crosssectional (D) contrast-enhanced images demonstrate a floating embolus (arrowheads) in the center of the common femoral artery (arrow). Due to its superior spatial resolution, contrast-enhanced ultrasonography could be used to exclude the possibility of arterial dissection. 
using CEUS of the carotid artery and peripheral vessels improve the delineation of vascular disorders in selected cases. It is a fast, nonionizing, cost effective imaging modality with almost no contraindications. The use of an ultrasound contrast agent increases the sensitivity of ultrasonography in vascular diseases and overcomes some limitations in the detection of blood flow within vascular structures. With the broader availability of contrast modes in modern ultrasound systems and the ongoing distribution of these systems to sonographers, CEUS is an already established, but still emerging imaging technique with a promising future.

ORCID: Johannes Rübenthaler: http://orcid.org/0000-0003-0832-5662; Maximilian Reiser: http://orcid.org/0000-0003-1098-8190; Dirk-André Clevert: http://orcid. org/0000-0003-3889-5447

\section{Conflict of Interest}

No potential conflict of interest relevant to this article was reported.

\section{References}

1. Rubenthaler J, Lutz J, Reiser M, Clevert DA. Title page: paraganglioma of the head and neck: follow-up of interventional procedures with CEUS. Ultraschall Med 2015;36:541-543.

2. Clevert DA, Johnson T, Michaely H, Jung EM, Flach PM, Strautz TI, et al. High-grade stenoses of the internal carotid artery: comparison of high-resolution contrast enhanced 3D MRA, duplex sonography and power Doppler imaging. Eur J Radiol 2006;60:379-386.

3. Clevert DA, Johnson T, Jung EM, Clevert DA, Flach PM, Strautz $\mathrm{TI}$, et al. Color Doppler, power Doppler and B-flow ultrasound in the assessment of ICA stenosis: comparison with 64-MD-CT angiography. Eur Radiol 2007;17:2149-2159.

4. Clevert DA, Rupp N, Reiser M, Jung EM. Improved diagnosis of vascular dissection by ultrasound B-flow: a comparison with color-coded Doppler and power Doppler sonography. Eur Radiol 2005;15:342-347.

5. Clevert DA, Kubisch C, Weckbach S, Frey U, Stock K, Reiser M. $B$-flow and color Doppler sonography findings in iatrogenic carotidjugular arteriovenous fistula. Clin Hemorheol Microcirc 2010;44:1925.

6. Jung EM, Kubale R, Ritter G, Gallegos MT, Jungius KP, Rupp N, et al. Diagnostics and characterisation of preocclusive stenoses and occlusions of the internal carotid artery with B-flow. Eur Radiol 2007;17:439-447.

7. Jungius $K P$, Jung EM, Clevert DA. High-grade stenosis of the internal carotid artery: ultrasonographic characterization. Praxis (Bern 1994) 2006;95:801-808.

8. Schulte-Altedorneburg G, Clevert DA. Color duplex sonography of extracranial brain-supplying arteries. Radiologe 2009;49:10161023.
9. Gurm HS, Yadav JS, Fayad P, Katzen BT, Mishkel GJ, Bajwa TK, et al. Long-term results of carotid stenting versus endarterectomy in high-risk patients. N Engl J Med 2008;358:1572-1579.

10. Eisenberg RL, Nemzek WR, Moore WS, Mani RL. Relationship of transient ischemic attacks and angiographically demonstrable lesions of carotid artery. Stroke 1977;8:483-486.

11. Adams HP Jr, Bendixen BH, Kappelle LJ, Biller J, Love BB, Gordon $D L$, et al. Classification of subtype of acute ischemic stroke: definitions for use in a multicenter clinical trial. TOAST. Trial of Org 10172 in Acute Stroke Treatment. Stroke 1993;24:35-41.

12. Meerwaldt R, Hermus L, Reijnen MM, Zeebregts CJ. Carotid endarterectomy: current consensus and controversies. Surg Technol Int 2010;20:283-291.

13. Hermus L, van Dam GM, Zeebregts CJ. Advanced carotid plaque imaging. Eur J Vasc Endovasc Surg 2010;39:125-133.

14. Krinsky G. Gadolinium-enhanced three-dimensional magnetic resonance angiography of the thoracic aorta and arch vessels: a review. Invest Radiol 1998;33:587-605.

15. Krinsky G, Rofsky NM. MR angiography of the aortic arch vessels and upper extremities. Magn Reson Imaging Clin N Am 1998;6:269-292.

16. Saloner D. Determinants of image appearance in contrastenhanced magnetic resonance angiography: a review. Invest Radio 1998;33:488-495.

17. Endarterectomy for asymptomatic carotid artery stenosis. Executive Committee for the Asymptomatic Carotid Atherosclerosis Study. JAMA 1995;273:1421-1428.

18. Moore WS, Barnett HJ, Beebe HG, Bernstein EF, Brener BJ, Brott $T$, et al. Guidelines for carotid endarterectomy: a multidisciplinary consensus statement from the Ad Hoc Committee, American Heart Association. Circulation 1995;91:566-579.

19. Kent KC. Clinical practice: abdominal aortic aneurysms. N Engl J Med 2014;371:2101-2108.

20. Clevert DA, Horng A, Reiser MF. Ultrasound imaging of the abdominal aorta. Radiologe 2009;49:1024-1032.

21. Clevert DA, Horng A, Kopp R, Schick K, Meimarakis G, Sommer WH, et al. Imaging of endoleaks after endovascular aneurysm repair (EVAR) with contrast-enhanced ultrasound (CEUS). Radiologe 2009;49:1033-1039.

22. Clevert DA, Horng A, Clevert DA, Jung EM, Sommer WH, Reiser M. Contrast-enhanced ultrasound versus conventional ultrasound and MS-CT in the diagnosis of abdominal aortic dissection. Clin Hemorheol Microcirc 2009:43:129-139.

23. Clevert DA, Helck A, D'Anastasi M, Gurtler V, Sommer WH, Meimarakis $G$, et al. Improving the follow up after EVAR by using ultrasound image fusion of CEUS and MS-CT. Clin Hemorheol Microcirc 2011;49:91-104.

24. Clevert DA, Gurtler VM, Meimarakis G, D'Anastasi M, Weidenhagen $R$, Reiser MF, et al. Classification of endoleaks in the follow-up 
after EVAR using the time-to-peak of the contrast agent in CEUS examinations. Clin Hemorheol Microcirc 2013;55:183-191.

25. Filardo G, Powell JT, Martinez MA, Ballard DJ. Surgery for small asymptomatic abdominal aortic aneurysms. Cochrane Database Syst Rev 2015;(2):CD001835.

26. Powell JT, Brown LC, Forbes JF, Fowkes FG, Greenhalgh RM, Ruckley $\mathrm{CV}$, et al. Final 12-year follow-up of surgery versus surveillance in the UK Small Aneurysm Trial. Br J Surg 2007;94:702-708.

27. Cantisani V, Grazhdani H, Clevert DA, lezzi R, Aiani L, Martegani A, et al. EVAR: benefits of CEUS for monitoring stent-graft status. Eur J Radiol 2015;84:1658-1665.

28. Cantisani V, David E, Mauro L, D'Ambrosio F, Clevert DA. CEUS: what is its role in abdominal aortic diseases? Med Ultrason 2015;17:419-421.

29. Chandrasekar B, Doucet S, Bilodeau L, Crepeau J, deGuise P, Gregoire J, et al. Complications of cardiac catheterization in the current era: a single-center experience. Catheter Cardiovasc Interv 2001;52:289-295.

30. Heintzen MP, Strauer BE. Peripheral arterial complications after heart catheterization. Herz 1998;23:4-20.

31. Neise M, Ranke C, Laschewski F, Trappe HJ. Pseudoaneurysm with associated arteriovenous fistula after transfemoral puncture. Med Klin (Munich) 1998;93:107-110.

32. Righini M, Quere I, Laroche JP. Treatment of postcatheterization femoral false aneurysms. J Mal Vasc 2004;29:63-72.

33. Thalhammer C, Kirchherr AS, Uhlich F, Waigand J, Gross CM. Postcatheterization pseudoaneurysms and arteriovenous fistulas: repair with percutaneous implantation of endovascular covered stents. Radiology 2000;214:127-131.

34. Perings SM, Kelm M, Jax T, Strauer BE. A prospective study on incidence and risk factors of arteriovenous fistulae following transfemoral cardiac catheterization. Int J Cardiol 2003;88:223228.

35. Greis C. Ultrasound contrast agents as markers of vascularity and microcirculation. Clin Hemorheol Microcirc 2009;43:1-9.

36. Greis C. Summary of technical principles of contrast sonography and future perspectives. Radiologe 2011;51:456-461.

37. Horng A, Reiser M, Clevert DA. Current developments in vascular ultrasound. Radiologe 2009;49:998-1004.

38. Piscaglia F, Bolondi L; Italian Society for Ultrasound in Medicine and Biology (SIUMB) Study Group on Ultrasound Contrast Agents. The safety of Sonovue in abdominal applications: retrospective analysis of 23188 investigations. Ultrasound Med Biol 2006;32:1369-1375.

39. ter Haar G. Safety and bio-effects of ultrasound contrast agents. Med Biol Eng Comput 2009;47:893-900.

40. Ravine D, Gibson RN, Donlan J, Sheffield LJ. An ultrasound renal cyst prevalence survey: specificity data for inherited renal cystic diseases. Am J Kidney Dis 1993;22:803-807.

41. Fine-Edelstein IS, Wolf PA, O'Leary DH, Poehlman $\mathrm{H}$, Belanger AJ,
Kase CS, et al. Precursors of extracranial carotid atherosclerosis in the Framingham Study. Neurology 1994;44:1046-1050.

42. Borisch I, Horn M, Butz B, Zorger N, Draganski B, Hoelscher T, et al. Preoperative evaluation of carotid artery stenosis: comparison of contrast-enhanced MR angiography and duplex sonography with digital subtraction angiography. AJNR Am J Neuroradiol 2003;24:1117-1122.

43. Polak JF. Carotid ultrasound. Radiol Clin North Am 2001;39:569589.

44. Lee W. General principles of carotid Doppler ultrasonography. Ultrasonography 2014;33:11-17.

45. Schminke U, Motsch L, Griewing B, Gaull M, Kessler C. Threedimensional power-mode ultrasound for quantification of the progression of carotid artery atherosclerosis. J Neurol 2000;247:106-111.

46. Hetzel A, Eckenweber B, Trummer B, Wernz M, Schumacher M, von Reutern $\mathrm{G}$. Colour-coded duplex sonography of preocclusive carotid stenoses. Eur J Ultrasound 1998;8:183-191.

47. North American Symptomatic Carotid Endarterectomy Trial Collaborators. Beneficial effect of carotid endarterectomy in symptomatic patients with high-grade carotid stenosis. N Engl J Med 1991;325:445-453.

48. Neff KW, Kilian AK, Meairs S, Duber C. Correlation of duplex sonographic stenosis grading by means of cross-sectional analysis and MR-tomographic blood volume flow quantification in unilateral stenosis of the internal carotid artery. Rofo 2005;177:992-999.

49. Grant EG, Benson CB, Moneta GL, Alexandrov AV, Baker JD, Bluth El, et al. Carotid artery stenosis: gray-scale and Doppler US diagnosis: Society of Radiologists in Ultrasound Consensus Conference. Radiology 2003;229:340-346.

50. Hwang CS, Liao KM, Lee JH, Tegeler CH. Measurement of carotid stenosis: comparisons between duplex and different angiographic grading methods. J Neuroimaging 2003;13:133-139.

51. Piscaglia F, Nolsoe C, Dietrich CF, Cosgrove DO, Gilja OH, Bachmann Nielsen M, et al. The EFSUMB Guidelines and Recommendations on the Clinical Practice of Contrast Enhanced Ultrasound (CEUS): update 2011 on non-hepatic applications. Ultraschall Med 2012;33:33-59.

52. Clevert DA, Sommer WH, Helck A, Saam T, Reiser M. Improved carotid atherosclerotic plaques imaging with contrast-enhanced ultrasound (CEUS). Clin Hemorheol Microcirc 2011;48:141-148.

53. Clevert DA, Sommer WH, Zengel P, Helck A, Reiser M. Imaging of carotid arterial diseases with contrast-enhanced ultrasound (CEUS). Eur J Radiol 2011;80:68-76.

54. Clevert DA, Paprottka P, Sommer WH, Helck A, Reiser MF, Zengel P. The role of contrast-enhanced ultrasound in imaging carotid arterial diseases. Semin Ultrasound CT MR 2013;34:204-212.

55. Rafailidis V, Pitoulias G, Kouskouras K, Rafailidis D. Contrastenhanced ultrasonography of the carotids. Ultrasonography 


\section{5;34:312-323.}

56. AbuRahma AF, Abu-Halimah S, Bensenhaver J, Dean LS, Keiffer T, Emmett M, et al. Optimal carotid duplex velocity criteria for defining the severity of carotid in-stent restenosis. J Vasc Surg 2008;48:589-594.

57. van der Vaart MG, Meerwaldt R, Reijnen MM, Tio RA, Zeebregts CJ. Endarterectomy or carotid artery stenting: the quest continues. Am J Surg 2008;195:259-269.

58. Gray WA, Hopkins LN, Yadav S, Davis T, Wholey M, Atkinson R, et al. Protected carotid stenting in high-surgical-risk patients: the ARCHeR results. J Vasc Surg 2006;44:258-268.

59. Yadav JS, Wholey MH, Kuntz RE, Fayad P, Katzen BT, Mishkel GJ, et al. Protected carotid-artery stenting versus endarterectomy in highrisk patients. N Engl J Med 2004;351:1493-1501.

60. Moore WS, Kempczinski RF, Nelson JJ, Toole JF. Recurrent carotid stenosis: results of the asymptomatic carotid atherosclerosis study. Stroke 1998;29:2018-2025.

61. Groschel K, Riecker A, Schulz JB, Ernemann U, Kastrup A. Systematic review of early recurrent stenosis after carotid angioplasty and stenting. Stroke 2005;36:367-373.

62. Roubin GS, New G, lyer SS, Vitek JJ, Al-Mubarak N, Liu MW, et al. Immediate and late clinical outcomes of carotid artery stenting in patients with symptomatic and asymptomatic carotid artery stenosis: a 5-year prospective analysis. Circulation 2001;103:532537.

63. Wholey MH, Al-Mubarek N, Wholey MH. Updated review of the global carotid artery stent registry. Catheter Cardiovasc Interv 2003:60:259-266.

64. Zhou W, Felkai DD, Evans M, McCoy SA, Lin PH, Kougias P, et al. Ultrasound criteria for severe in-stent restenosis following carotid artery stenting. J Vasc Surg 2008;47:74-80.

65. Clevert DA, Sommer WH, Helck A, Reiser M. Duplex and contrast enhanced ultrasound (CEUS) in evaluation of in-stent restenosis after carotid stenting. Clin Hemorheol Microcirc 2011;48:199-208.

66. Armstrong PA, Bandyk DF, Johnson BL, Shames ML, Zwiebel BR, Back MR. Duplex scan surveillance after carotid angioplasty and stenting: a rational definition of stent stenosis. J Vasc Surg 2007;46:460-465.

67. Guillon B, Bousser MG. Epidemiology and pathophysiology of spontaneous cervical artery dissection. J Neuroradiol 2002;29:241249.

68. Dziewas R, Konrad C, Drager B, Evers S, Besselmann M, Ludemann $P$, et al. Cervical artery dissection: clinical features, risk factors, therapy and outcome in 126 patients. J Neurol 2003;250:11791184.

69. Lu CJ, Sun Y, Jeng JS, Huang KM, Hwang BS, Lin WH, et al. Imaging in the diagnosis and follow-up evaluation of vertebral artery dissection. J Ultrasound Med 2000;19:263-270.

70. Massalha K, Goyen M, Rudofsky G. Stenosis-jet can cause a dissection of the superficial femoral artery. Vasa 1999;28:131-133.

71. Schellinger PD, Schwab S, Krieger D, Fiebach JB, Steiner T, Hund EF, et al. Masking of vertebral artery dissection by severe trauma to the cervical spine. Spine (Phila Pa 1976) 2001;26:314-319.

72. Clevert DA, Jung EM, Johnson T, Kubale R, Rupp N, Schoenberg SO, et al. Cervical artery dissection: improved diagnosis by B-Flow ultrasound. Clin Hemorheol Microcirc 2007;36:141-153.

73. Clevert DA, Graser A, Jung EM, Stickel M, Reiser M. Value of ultrasound in the diagnosis of aneurysms of the extracranial internal carotid arteries. Clin Hemorheol Microcirc 2008;39:133146.

74. Rao TL, Wong AY, Salem MR. A new approach to percutaneous catheterization of the internal jugular vein. Anesthesiology 1977;46:362-364.

75. Sznajder Jl, Zveibil FR, Bitterman H, Weiner P, Bursztein S. Central vein catheterization: failure and complication rates by three percutaneous approaches. Arch Intern Med 1986;146:259-261.

76. Lopez-Quinones M, Bargallo X, Blasco J, Real MI, Gonzalez S, Bunesch $L$, et al. latrogenic carotid-jugular arteriovenous fistula: color Doppler sonographic findings and treatment with covered stent. J Clin Ultrasound 2006;34:301-305.

77. Ezri T, Szmuk P, Cohen Y, Simon D, Mavor E, Katz J, et al. Carotid artery-internal jugular vein fistula: a complication of internal jugular vein catheterization. J Cardiothorac Vasc Anesth 2001;15:231-232.

78. Clevert DA, Kubisch C, Meimarakis G, Zengel P, Reiser M. Improved visualization of carotid-jugular arteriovenous fistula by contrastenhanced ultrasound. Ultraschall Med 2010;31:610-612.

79. Li J, Mi D, Pu Y, Zou X, Pan Y, Soo Y, et al. Comparison of carotid atherosclerotic plaque characteristics between patients with first-time and recurrent acute ischaemic stroke using B-mode ultrasound. Neurol Res 2015;37:809-813.

80. Martinez-Sanchez P, Alexandrov AV. Ultrasonography of carotid plaque for the prevention of stroke. Expert Rev Cardiovasc Ther 2013;11:1425-1440.

81. Shalhoub J, Owen DR, Gauthier T, Monaco C, Leen EL, Davies AH. The use of contrast enhanced ultrasound in carotid arterial disease. Eur J Vasc Endovasc Surg 2010;39:381-387.

82. Giannoni MF, Vicenzini E, Citone M, Ricciardi MC, Irace L, Laurito A, et al. Contrast carotid ultrasound for the detection of unstable plaques with neoangiogenesis: a pilot study. Eur J Vasc Endovasc Surg 2009;37:722-727.

83. Coli S, Magnoni M, Sangiorgi G, Marrocco-Trischitta MM, Melisurgo $G$, Mauriello A, et al. Contrast-enhanced ultrasound imaging of intraplaque neovascularization in carotid arteries: correlation with histology and plaque echogenicity. J Am Coll Cardiol 2008;52:223230.

84. Xiong L, Deng YB, Zhu Y, Liu YN, Bi XJ. Correlation of carotid plaque neovascularization detected by using contrast-enhanced US with clinical symptoms. Radiology 2009;251:583-589. 
85. Shuman WP, Hastrup W Jr, Kohler TR, Nyberg DA, Wang KY, Vincent LM, et al. Suspected leaking abdominal aortic aneurysm: use of sonography in the emergency room. Radiology 1988;168:117-119.

86. Catalano O, Lobianco R, Cusati B, Siani A. Contrast-enhanced sonography for diagnosis of ruptured abdominal aortic aneurysm. AJR Am J Roentgenol 2005; 184:423-427.

87. Eichlisberger R, Frauchiger B, Schmitt H, Jager K. Aneurysma spurium following arterial catheterization: diagnosis and follow-up. Ultraschall Med 1992;13:54-58.

88. Hirano $Y$, Ikuta $S$, Uehara $H$, Nakamura $H$, Taniguchi M, Kimura A, et al. Diagnosis of vascular complications at the puncture site after cardiac catheterization. J Cardiol 2004;43:259-265.

89. Trubel W, Staudacher M, Magometschnigg H, Wolner E. Aneurysma spurium after iatrogenic arterial puncture: incidence, risk factors and surgical therapy. Wien Klin Wochenschr 1993;105:139-143.

90. Cronenwett JL, Murphy TF, Zelenock GB, Whitehouse WM Jr,
Lindenauer SM, Graham LM, et al. Actuarial analysis of variables associated with rupture of small abdominal aortic aneurysms. Surgery 1985;98:472-483.

91. Pagliariccio G, Catalini R, Giantomassi L, Angelini A. Management of pseudoaneurysm of the leg: is Color Doppler US enough? J Ultrasound 2010;13:61-65.

92. Brewster DC, Cambria RP, Moncure AC, Darling RC, LaMuraglia GM, Geller SC, et al. Aortocaval and iliac arteriovenous fistulas: recognition and treatment. J Vasc Surg 1991;13:253-264.

93. Mand'ak J, Lonsky V, Dominik J, Zacek P. Vascular complications of the intra-aortic balloon counterpulsation. Angiology 2005;56:6974.

94. Berry C, Kelly J, Cobbe SM, Eteiba H. Comparison of femoral bleeding complications after coronary angiography versus percutaneous coronary intervention. Am J Cardiol 2004;94:361363. 